\title{
FAKTOR-FAKTOR YANG BERPENGARUH TERHADAP NILAI KALKULUS MAHASISWA INSTITUT TEKNOLOGI DAN BISNIS STIKOM BALI
}

\author{
Gusti Ayu Made Arna Putri \\ Institut Teknologi Dan Bisnis Stikom Bali \\ Email: gustiayu.arna@gmail.com
}

\begin{abstract}
Characteristics of respondents were the focus of this study. Characteristics of the respondents are age, work status, high school background, and Calculus study time. Age and Calculus study time are on ratio scale, working status on nominal scale (Yes and No), high school background (Natural Sciences, Social Sciences, Engineering), and work status (Yes and No). The independent variables that have been identified then modeled against calculus score with multiple regression analysis. The variables that are modeled are then selected using a stepwise algorithm, thus obtaining the best model. The subjects studied in this study are students of two Calculus classes on the even semester at the STIKOM Bali Institute of Technology and Business. The purpose of this study is to see the factors that affect the students' Calculus score at the STIKOM Bali Institute of Technology and Business. The results in this study based on the respondents' characteristics are variable that significantly affect the Calculus score, that are Natural Sciences during high school and work status.
\end{abstract}

Keywords: Calculus, Multiple Regression Analysis

\begin{abstract}
ABSTRAK
Karakteristik responden menjadi fokus dalam penelitian ini. Karakteristik responden yang dicatat yaitu usia, status bekerja, latar belakang jurusan SMA, dan waktu belajar Kalkulus. Usia dan waktu belajar kalkulus dicatat dalam skala rasio, status bekerja dalam skala nominal (Ya dan Tidak), latar belakang jurusan SMA (IPA, IPS, Teknik), dan status bekerja (Ya dan Tidak). Variabel bebas yang telah teridentifikasi tersebut selanjutnya dimodelkan terhadap nilai kalkulus dengan analisis regresi berganda. Variabel yang dimodelkan lalu diseleksi menggunakan algoritma stepwise, sehingga memperoleh model terbaik. Subjek yang diteliti dalam penelitian ini yaitu dua kelas dari mahasiswa mata kuliah Kalkulus semester genap di Institut Teknologi dan Bisnis STIKOM Bali. Penelitian ini bertujuan untuk melihat faktorfaktor yang mempengaruhi nilai Kalkulus mahasiswa Institut Teknologi dan Bisnis STIKOM Bali. Hasil dalam penelitian ini berdasarkan karakteristik responden diperoleh variabel yang berpengaruh signifikan terhadap nilai kalkulus yaitu jurusan IPA saat SMA dan status bekerja. Kata kunci: Kalkulus, Analisis Regresi Berganda
\end{abstract}

\section{PENDAHULUAN}

Saat ini kemajuan dunia sangat dipengaruhi oleh teknologi. Teknologi menjadi salah satu faktor penentu majunya perkembangan dunia disegala bidang. Pesatnya perkembangan teknologi di negara berkembang seperti Indonesia dapat meningkatkan kualitas generasi penerus yang lebih produktif. Salah satunya teknologi berperan penting dalam tumbuh 
kembangnya dunia pendidikan.

Pendidikan merupakan hal yang menjadi perhatian utama bagi kehidupan masyarakat karena pendidikan dirasa mampu meningkatkan taraf hidup dan mencerdaskan bangsa. Semakin baik pendidikan suatu negara, maka semakin berkualis juga sumber daya manusia yang ada didalamnya. Kemampuan masyarakat dibidang pendidikan dapat diukur dalam berbagai aspek keahlian seperti dalam bidang ilmu atau pengajaran. Dikutip dari UndangUndang No.20, Pasal1, ayat 1, tahun 2003 tentang Sistem Pendidikan Nasional, yang berbunyi "demi mewujudkan suasana belajar dan proses pembelajaran secara sadar dan terencana sehingga peserta didik diharapkan mampu lebih aktif dalam pengembangan potensi diri."

Diungkapkan Oemar Hamalik (2006) dalam buku karyanya yang berjudul "Proses Belajar Mengajar" sistem pembelajaran dapat dipengaruhi dari beberapa unsur yaitu unsur manusiawi, kesediaan fasilitas, serta aturan yang saling terkait maka tujuan dari pembelajaran mampu dicapai. Salah satu hal yang dapat mempengaruhi keberhasilan suatu sistem pembelajaran yaitu dengan adanya kurikulum di kelas.

Kurikulum dalam pendidikan bertujuan untuk mengatur tentang bagaimana sistem pendidikan itu dilaksanakan baik dalam pendidikan formal maupun informal. Berbagai unsur yang berpengaruh dalam sumber daya pendidikan, keberadaan kurikulum menjadi salah satu unsur yang berkontribusi cukup besar dalam perwujudan kualitas potensi peserta didik yang berkualitas. Berbagai macam mata kuliah yang ada dalam kurikulum kampus, baik itu eksak maupun non eksak. Dari semua mata kuliah, ada satu mata kuliah yang memiliki persentase yang tidak disukai oleh peserta didik, yaitu mata kuliah kalkulus.

Kalkulus merupakan salah satu mata kuliah dari cabang ilmu matematika yang menganalisis masalah-masalah perubahan. Makna Kalkulus dalam bahasa latin yaitu calculus yang berarti "batu kecil". Kalkulus memuat tentang turunan, integral, limit, dan deret tak terhingga. Cabang utama dari Kalkulus terbagi menjadi dua bagian yaitu Kalkulus Integral dan Kalkulus Deferensial. Kedua bagian tersebut saling berhubungan melalui teori dasar. Mata kuliah kalkulus sering kali menjadi masalah bagi mahasiswa dalam memperoleh nilai akhir karena nilai yang diperoleh untuk mata kuliah ini relatif kecil. Sehingga muncul pemikiran bahwa terdapat faktor yang menjadi penyebab hal tersebut terjadi.

Menurut Slameto (2010) faktor-faktor yang dipengaruhi oleh prestasi belajar siswa digolongkan menjadi dua, yaitu faktor internal dan faktor eksternal. Faktor internal adalah faktor yang ada didalam setiap diri individu sedangkan faktor eksternal adalah faktor yang ada 
di luar individu. Adapun faktor-faktor atau variabel yang diidentifikasi berpengaruh terhadap nilai Kalkulus dalam penelitian ini adalah usia, waktu belajar Kalkulus, status bekerja, latar belakang jurusan SMA. Menurut Purwanto (1990) setiap individu yang memiliki kecakapan dan pengetahuan dapat semakin meningkat dan dikatakan terlatih jika orang tersebut seringkali mengulang sesuatu hal yang dikerjakan.

Dari uraian latar belakang masalah tersebut maka peneliti tertarik untuk mengambil topik penelitian tentang eksperimen pembelajaran pada mata kuliah Kalkulus. Karakteristik responden menjadi perhatian peneliti dengan melihat faktor-faktor yang mempengaruhi nilai mahasiswa Kalkulus. Faktor-faktor yang mempengaruhi minimnya nilai Kalkulus akan menjadi perhatian dalam memperbaiki kinerja mahasiswa di Institut Teknologi dan Bisnis STIKOM Bali.

\section{METODOLOGI}

\subsection{Model Konseptual}

Model konseptual adalah kerangka pola pikir yang berfungsi dalam penyelesaian suatu kasus. Pada umumnya kerangka penelitian digunakan dalam pendekatan ilmiah dan hubungan antar variabel didalam proses analisis sangat diperhatikan,

Kerangka berpikir dalam penelitian ini disajikan dalam bentuk Gambar 1.

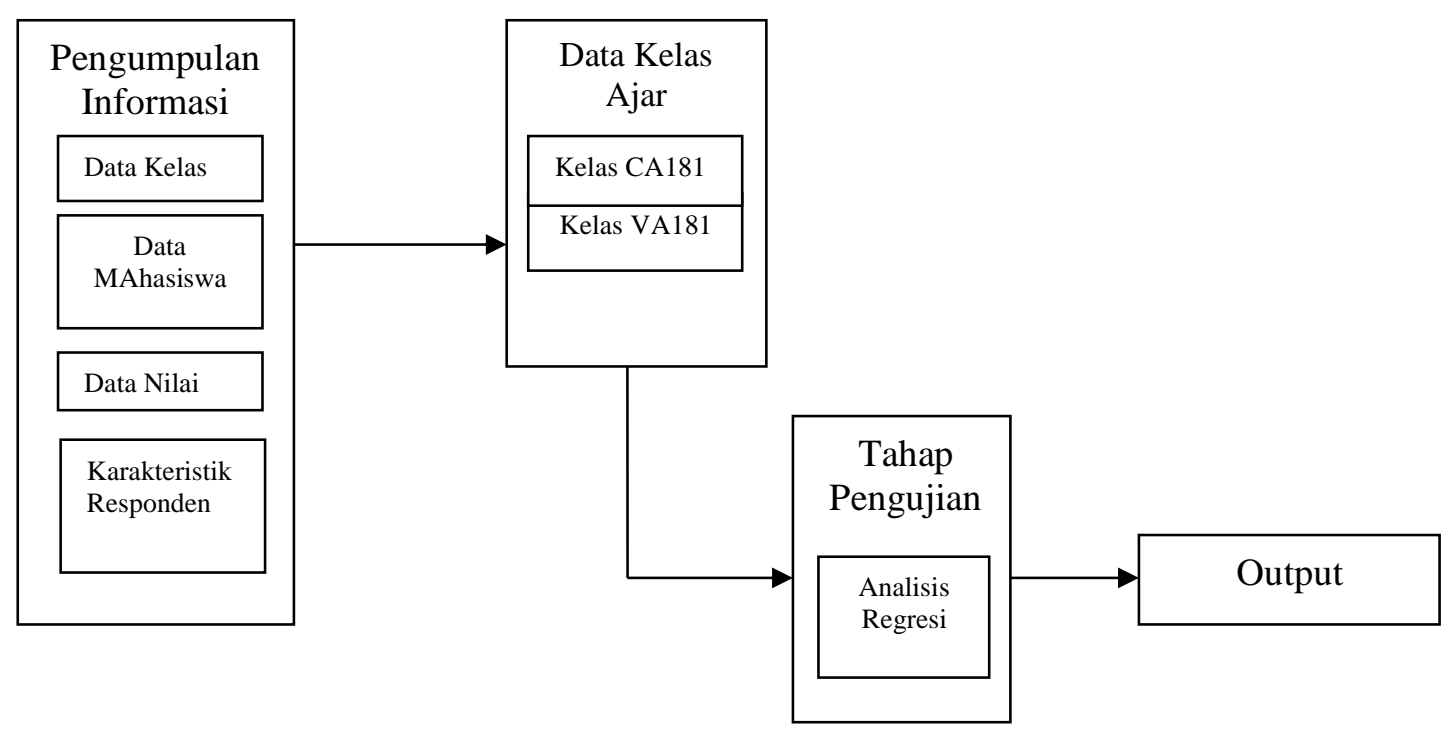

Gambar 1 Model Konseptual Penelitian

1. Pengumpulan Informasi 
Penelitian ini diawali dengan pengumpulan informasi mulai dari data kelas ajar, data mahasiswa hingga memperoleh hasil mahasiswa berupa nilai akhir. Selain itu, tiap mahasiswa dicatat karakteristik responden seperti, usia, status bekerja, latar belakang jurusan SMA, dan waktu belajar kalkulus. Usia dan waktu belajar kalkulus dicatat dalam skala rasio, status bekerja dalam skala nominal (Ya dan Tidak), latar belakang jurusan SMA (IPA, IPS, Teknik), dan status bekerja (Ya dan Tidak).

2. Data Kelas

Penelitian ini mengambil dua kelas dalam semester genap tahun 2019 di Institut Teknologi dan Bisnis STIKOM Bali. Kelas Ajar yang menjadi subjek penelitian yaitu kelas Kalkulus CA181 dan VA181.

3. Tahan Pengujian.

Pengujian awal dilakukan dengan identifikasi variabel bebas, selanjutnya variabel bebas yang telah teridentifikasi dimodelkan terhadap nilai kalkulus dengan analisis regresi berganda. Variabel yang dimodelkan lalu diseleksi menggunakan algoritma stepwise, sehingga memperoleh model terbaik.

4. Output

Diperoleh karakteristik responden yang berpengaruh terhadap prestasi belajar mahasiswa Kalkulus di kelas CA181 dan VA181.

\subsection{Sistematika Penelitian}

Penelitian ini adalah penelitian yang mencatat karakteristik responden pada mahasiswa kelas Kalkulus. Pencatat karakteristik responden tersebut dimulai dari tahapan pra proposal yang terdiri dari identifikasi kasus, studi literatur, dan rumusan masalah. Kemudian dilanjutkan dengan penulisan proposal penelitian. Tahapan penelitian selanjutnya yaitu pengusulan proposal penelitian. Publikasi penelitian ini ditargetkan ke jurnal ilmiah nasional. Penelitian ini menggunakan data prestasi mahasiswa dalam kurun waktu satu semester. Berikut tahapan-tahapan pada penelitian ini yaitu:

1. Subjek dalam penelitian ini adalah dua kelas kalkulus yaitu kelas CA181 dan VA181.

2. Melakukan pencatatan karakateristik responden pada mahasiswa di kedua kelas tersebut.

3. Lakukan pemodelan terhadap nilai kalkulus ditinjau dari karakteristik responden.

4. Uji dengan analisis regresi berganda. Variabel yang dimodelkan lalu diseleksi menggunakan algoritma stepwise, sehingga memperoleh model terbaik. 
Secara umum, tahapan-tahapan dalam penelitian tersebut akan dijelaskan melalui diagram pada Gambar 2.

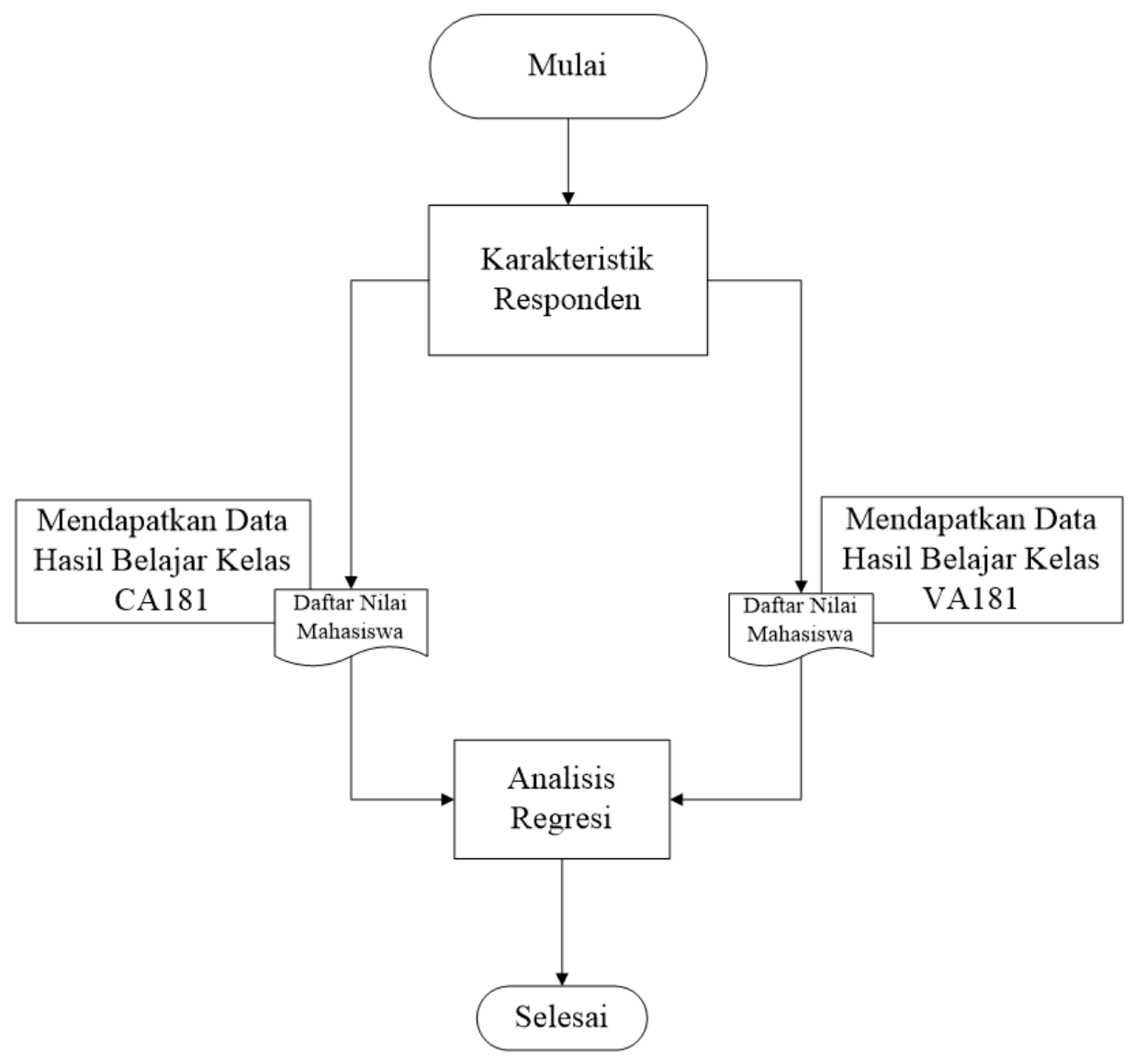

\section{Gambar 2 Diagram Sistematika Penelitian}

\subsection{Tempat dan Waktu Penelitian}

Penelitian ini dilakukan di Institut Teknologi dan Bisnis STIKOM Bali dalam kurun waktu sembilan bulan.

\subsection{Data}

\subsubsection{Jenis Data}

Berdasarkan sumber data, peneliti menggunakan data primer yang diperoleh dari sumber data langsung. Jadi untuk mendapatkan data primer, peneliti harus mengumpulkan nilai dari mahasiswa kelas Kalkulus secara langsung. Sedangkan berdasarkan sifat, data yang digunakan adalah data kuantitatif yaitu data yang berbentuk bilangan atau angka yang diperoleh berdasarkan nilai mahasiswa Kelas Kalkulus di Institut Teknologi Dan Bisnis Stikom Bali.

\subsubsection{Teknik Pengumpulan Data}

Teknik pengumpulan data menggunakan teknik observasi, dimana peneliti 
mengumpulkan data dengan pengamatan secara langsung di kelas. Teknik ini digunakan untuk penelitian yang bertujuan untuk mempelajari perilaku mahasiswa, proses belajar, dan karakteristik responden.

\subsection{Teknik Analisis Data}

Teknik analisis dalam penelitian ini yaitu teknik analisis data statistik. Teknik analisis data statistik merupakan langkah yang dilakukan dengan pengumpulan data atau fakta, pengolahan, penyajian, dan analisis, sehingga nantinya dapat ditarik suatu kesimpulan dan pembuatan keputusan yang cukup beralasan berdasarkan fakta dan analisis di kelas.

\section{HASIL DAN PEMBAHASAN}

\subsection{Faktor-Faktor yang Mempengaruhi Nilai Kalkulus}

Variabel yang diidentifikasi mempengaruhi nilai Kalkulus adalah usia, waktu belajar kalkulus, status bekerja, latar belakang jurusan SMA. Variabel bebas yang telah teridentifikasi selanjutnya dimodelkan terhadap nilai kalkulus dengan analisis regresi berganda. Variabel yang dimodelkan lalu diseleksi menggunakan algoritma stepwise, sehingga memperoleh model terbaik sebagai berikut:

Tabel 1 Uji Koefisien Parameter dan Goodness of Fit Model Regresion

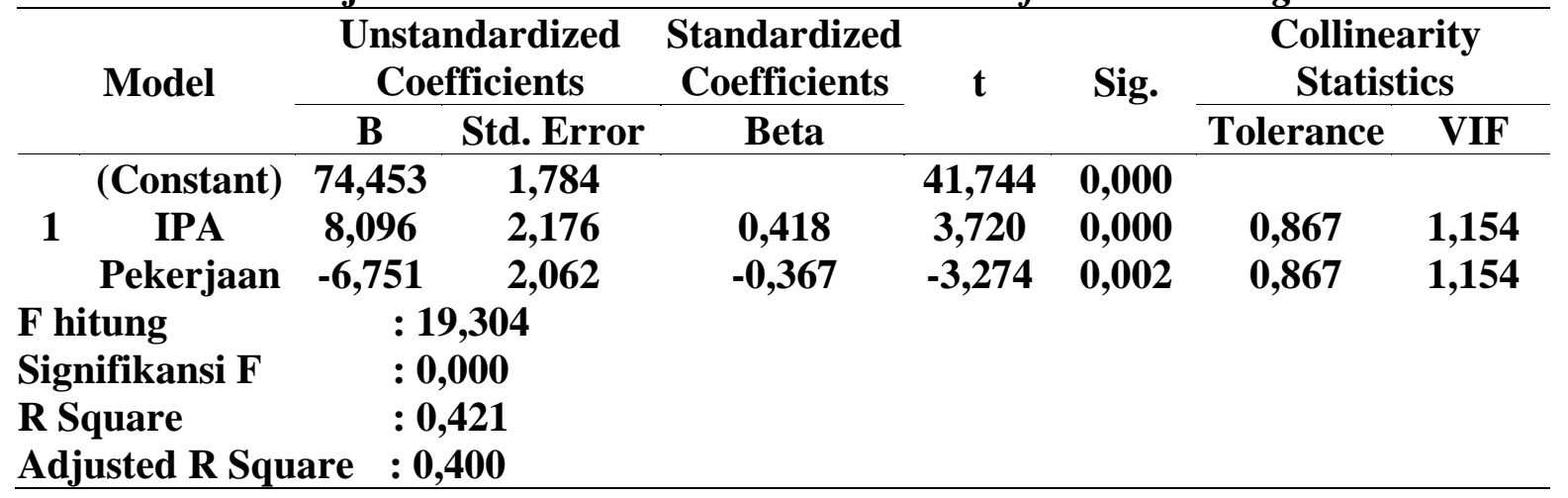

Berdasarkan Tabel 1, diperoleh variabel yang berpengaruh signifikan terhadap nilai Kalkulus. Variabel IPA dengan nilai t hitung sebesar 3,720 dan signifikansi sebesar 0,000, menandakan bahwa mahasiswa dengan latar belakang IPA cenderung memiliki nilai kalkulus lebih besar dibandingkan mahasiswa dengan latar belakang teknik. Variabel pekerjaan memiliki nilai $t$ hitung sebesar -3,274 dengan nilai signifikansi sebesar 0,002, menandakan bahwa mahasiswa yang tidak bekerja cenderung memiliki nilai kalkulus yang lebih besar dibandingkan dengan mahasiswa yang bekerja.

Model yang diperoleh dinyatakan layak terlihat dari nilai $\mathrm{F}$ hitung sebesar 19,304 dengan signifikansi sebesar 0,000. Selain itu, nilai $R$ square sebesar 0,421 dan adjusted $\mathrm{R}$ 


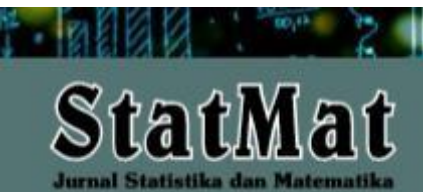

P-ISSN: 2655-3724

STATMAT (Jurnal Statistik dan Matematika), Vol. 2, No. 1, 2020

Halaman: 14-20

@Prodi S-1 Matematika FMIPA Unpam

square sebesar 0,400 menandakan bahwa hubungan masuk dalam kategori moderat. Hal ini berarti variabel IPA dan Pekerjaan berpengaruh sebesar $42,1 \%$ terhadap nilai kalkulus, sedangkan 57,9\% sisanya dipengaruhi oleh variabel lain yang tidak masuk dalam model.

\section{SIMPULAN}

Berdasarkan hasil analisis regresi berganda berdasarkan karakteristik responden diperoleh variabel yang berpengaruh signifikan terhadap nilai kalkulus yaitu jurusan IPA saat SMA dan status bekerja.

\section{DAFTAR PUSTAKA}

Hamalik, O. 2006. Proses Belajar Mengajar, Jakarta: PT. Bumi Aksara.

Purwanto, N. 1990. Psikologi Pendidikan, Jakarta: PT Remaja Rosdakarya.

Slameto, 2010. Belajar dan Faktor-faktor yang Mempengaruhinya, Jakarta: PT Rineka Cipta. 